Check for updates

Cite this: RSC Adv., 2017, 7, 46246

Received 8th November 2016

Accepted 15th August 2017

DOI: 10.1039/c6ra26508a

rsc.li/rsc-advances

\section{Improving the activity of endoglucanase I (EGI) from Saccharomyces cerevisiae by DNA shuffling}

\begin{abstract}
Xu Wang, (D) ab Liang Rong, ${ }^{c}$ Mingfu Wang, ${ }^{a}$ Yingjie Pan, ${ }^{a}$ Yong Zhao*a and Fang Tao*b
To enhance the specific endo- $\beta-1,4$-glucanase activity (EGI) of three mixed substances: Trichoderma sp. (Trichoderma reesei, Trichoderma longibrachiatum, and Trichoderma pseudokoningii), we optimized the efficiency of the encoding gene, eg1, using DNA shuffling and Saccharomyces cerevisiae INVSc1 as a host. One variant, $\mathrm{SEGl}_{8}$ (the high activity protein encoded by eg1 gene using DNA shuffling) was found through screening approximately 1000 variants. The extracellular enzyme work of $\mathrm{SEGl}_{8}$ reached its highest level when cultured for $96 \mathrm{~h}$, at $50{ }^{\circ} \mathrm{C}$ and a $\mathrm{pH}$ of 5.6 , akin to the wild types. Clone harboring of the best mutant $\mathrm{SEGl}_{8}$ (selected via first-round mutagenesis) produced 169-257\% more activity than transformants with three wild-type EGIs. Mutant $\mathrm{SEGl}_{8}$ produced by the clone showed broad pH stability (5.6-6.6) while performing comparable thermotolerance $\left(60-70{ }^{\circ} \mathrm{C}\right)$ compared to wild EGls; it also showed a high homology of 95\%,96\%, and 97\%, identical to the EGI of T. reesei, T. longibrachiatum, and T. pseudokoningii, respectively. Analysis of the sequences indicated that four point mutations causing amino acid substitution (V10A/G100S/F192L/S318G) were replaced. The major structure of the active site in $\mathrm{SEGl}_{8}$ was comprised of loop regions, with the same location as $\beta$-helix in NTEGI (the protein encoded by eg1 genes in $T$. reesei). It has been suggested that the mutation S318G might affect substrate binding and improved actions based on an analysis of the predicted 3D structural-modeling of SEGI 8 . Overall, this novel system could facilitate cellulose activity and create a foundation for constructing an efficient cellulose degradation system.
\end{abstract}

\section{Introduction}

Cellulose, the most abundant polysaccharide, has the largest number of renewable resources in nature. There are about 10 billion tons of dry vegetal products produced in the world every year, of which more than half are cellulose or hemicellulose. ${ }^{1}$ However, the majority of agricultural products are discarded, and only a small portion is utilized. Thus, it is important to develop efficient ways to utilize these renewable resources. A process of cellulose degradation would provide a significant contribution toward solving these environmental and ecological problems. $^{2}$

The degradation of cellulose by microorganisms has been considered a major step in Earth's carbon cycle. According to the most widely accepted view, the hydrolysis of cellulose provides an ideal way to achieve this degradation with minimal contamination. It is known that the enzymatic hydrolysis of cellulose is a complex heterogeneous reaction and that cellulose can be degraded by three major types of enzyme components

${ }^{a}$ College of Food Science and Technology, Shanghai Ocean University, Shanghai, China.E-mail: yzhao@shou.edu.cn

${ }^{b}$ School of Life Sciences, Anhui Agricultural University, Anhui, China. E-mail: taofang007@126.com

'USC School of Pharmacy, University of Southern California, Los Angeles, 1985 Zonal Ave, USA acting synergistically at the substrate level: endoglucanases (endo- $\beta$-1,4-glucanases; EG), cellobiohydrolases (exo- $\beta$-1,4-glucanase; $\mathrm{CBH}$ ), and $\beta-1,4$-glucosidase (BG). ${ }^{3-6}$ Endoglucanases catalyze the hydrolysis of internal bonds inside the cellulose chains and randomly yield new small-molecular cellulose. Cellobiohydrolases especially attack the nonreducing chain ends, releasing cellobiose, and $\beta$-glucosidase active on the cellobiose releasing glucose monomer units from it. ${ }^{2,7}$ Contributing to the first step of bioconversion, endoglucanases play an important role in degrading cellulose. Four endoglucanases, EGI (Cel7B), EGII (Cel5A), EGIII (Cel12A), and EGV (Cel45A), represent, respectively, approximately $15 \%, 10 \%, 1 \%$, and $<1 \%$ of the total cellulase content. ${ }^{\mathbf{8} 9}$ Importantly, EGI consists of two distinct domains connected by an $O$-glycosylated flexible-linker region, namely a cellulose-binding domain (CBD) and a larger catalytic domain (CD). EGI also has the most efficient hydrolysis capacity for crystalline cellulose in the fungal cellulase systems known as glycosyl hydrolase family 7 according to the classification by Henrissat et al. ${ }^{\mathbf{1 0 , 1 1}}$ For example, EGI is the major endoglucanase in Trichoderma reesei, which accounts for $510 \%$ of the total amount of cellulolytic enzymes produced by this important fungus. ${ }^{12}$ Therefore, research on EGI by protein engineers can greatly help in creating a way to degrade cellulose efficiently.

Many organisms can digest cellulose, including insects, microbes, actinomycetes, fungi, and animals..$^{\mathbf{1 3}-15}$ One novel 
endoglucanase that has been reported is encoded by the Ba-ega gene in Bacillus spp., and although it has a high temperature stability, its activity is low. In other words, the majority of endoglucanases in Bacillus spp. have no activity on cellulose. ${ }^{16}$ Many cellulase genes have also been cloned from animal origins such as termites, nematodes, longicorn beetles, and others. ${ }^{17,18}$ However, because of the complex post-translational modification state, the cellulases from animal origins have lower expression levels. Therefore, the utilization of cellulases from fungi is considered an international hot spot, especially those from Trichoderma spp. ${ }^{\mathbf{1 9 , 2 0}}$

Many studies in the past have reported on cellulase genes from Trichoderma spp. being successfully expressed in Saccharomyces cerevisiae and Escherichia coli. ${ }^{21,22}$ The technique was recently used to screen cellulases in directedmutagenesis mutants for increased enzymatic activity. Directed evolution is regarded as a powerful alternative to other methods that optimize for enzyme properties by generating random genetic libraries and screening for specific characteristics. $^{23,24}$ Oligonucleotide-directed mutagenesis, error-prone PCR, and DNA shuffling are the primary screening systems for directed evolution to generate highly recombined genes and evolved enzymes. ${ }^{25,26}$ DNA shuffling has a novel ability to rapidly recombine homologous genes in vitro, making it a convenient and effective method for site-directed mutagenesis. $^{27}$ Thus far, only error-prone PCR and oligonucleotide-directed mutagenesis have been applied to improve the activity of endoglucanases. Nakazawa et al. showed that the specific activity of EGIII in $T$. reesei was enhanced by the directed evolution of its encoding gene (egI3) using error-prone PCR and screening for activity in E. coli. ${ }^{28}$ Lin et al. obtained two endoglucanase Cel8M mutations by screening approximately 1000 directed-evolution variants in E. coli. ${ }^{29}$ The endoglucanase I and II genes (eg1 or Cel7B and eg11 or Cel5A) of T. reesei QM6a were cloned and successfully expressed in S. cerevisiae under the transcriptional control of yeast ENO1 through random mutagenesis of the plasmid. ${ }^{30}$ However, no studies have reported engineering EGI by using DNA shuffling for directed evolution.
In this study, we first tried to perform the directed evolution trial on endoglucanase I (EGI) from three Trichoderma sp. (T. reesei, $T$. pseudokoningii and $T$. longibrachiatum) to improve cellulose hydrolysis, by employing DNA shuffling and screening. One EGI variant was found to higher enzymatic compared to the wild type versions when both the transformant variants and wild types were expressed in the yeast strain $S$. cerevisiae INVSc1 and extracellular activity displayed by this host. We reported here that this research by focused mutagenesis could gain new insights in the relationship between whole EGI protein and enzymatic activity.

\section{Material and methods}

\subsection{Strains, media, and cultivation}

The three Trichoderma spp. strains (Trichoderma reesei, Trichoderma pseudokoningii, and Trichoderma longibrachiatum) were purchased from the China General Microbiological Culture Collection Center (Beijing, China) (Table 1). Escherichia coli DH5 $\alpha$ was used as the cloning host for the recombinant DNA manipulations and plasmid propagation. The strain was cultivated in Luria-Bertani broth supplemented with $100 \mu \mathrm{g} \mathrm{mL}$ ampicillin at $37{ }^{\circ} \mathrm{C}^{31}$ Saccharomyces cerevisiae INVSc1 (Thermo Fisher Scientific, Lafayette, Co.) was used as the expression host for the cellulases and was cultured in YPD medium $\left(10 \mathrm{~g} \mathrm{~L}^{-1}\right.$ yeast extract, $20 \mathrm{~g} \mathrm{~L}^{-1}$ peptone, and $20 \mathrm{~g} \mathrm{~L}^{-1}$ glucose) on a rotary shaker $(150 \mathrm{rpm})$ at $30{ }^{\circ} \mathrm{C}$ in $200 \mathrm{~mL}$ Erlenmeyer flasks. The yeast strains were maintained on YPD agar $\left(15 \mathrm{~g} \mathrm{~L}^{-1}\right)$ plates. The yeast transformants were selected on synthetic complete medium that lacked uracil (SC-U) with $2 \%$ glucose and were grown at $30{ }^{\circ} \mathrm{C}$ for $24-48 \mathrm{~h} .{ }^{32}$ Two percent galactose was added to SC-U to screen for positive transformants following the introduction of the recombinant DNA. Enzymatic activity was detected on SC-U agar $\left(20 \mathrm{~g} \mathrm{~L}^{-1}\right)$ plates containing $2 \%$ galactose.

\subsection{Plasmid construction}

Genomic DNA from the Trichoderma spp. was extracted by the standard protocols provided with the MiniBEST Plant Genomic Extraction Kit (Takara, Japan). The enzymes used for the

Table 1 Microbial strains and plasmids used in this study

\begin{tabular}{lll}
\hline Strain or plasmid & Genotype & Source/reference \\
\hline Strains & & \\
Trichoderma reesei (AS3.3711) & Wild type & C.G.M.C.C.C ${ }^{a}$ \\
Trichoderma pseudokoningii (AS3.3002) & Wild type & C.G.M.C.C.C. \\
Trichoderma longibrachiatum (AS3.1029) & Wild type & C.G.M.C.C.C. \\
Escherichia coli DH5 $\alpha$ & supE44 $\Delta$ lacU169 (\$80lacZDM15) hsdR17 & 31 \\
Saccharomyces cerevisiae INVSc1 & recA1 endA1gyrA96 thi-1 relA1 & Thermo Fisher corporation
\end{tabular}

Plasmids

pMD-18T

pYES- $\alpha$-factor
Clone vector

Expression vector (pYES2.0 with $\alpha$-factor signal peptide)
Takara corporation

This laboratory

${ }^{a}$ China General Microbiological Culture Collection Center (Beijing, China). 
restriction digests and ligations were purchased from Takara Biotechnology (Takara, Japan). Polymerase chain reactions (PCR) were performed with a Biometra TGradient PCR System using Takara Premix Taq ${ }^{\mathrm{TM}}$ version 2.0 polymerase (Takara, Japan) according to the supplier's specifications. The primers used in this study are listed in Table 2. A sketch of the splice overlap extension (SOE)-PCR process is shown in Fig. 1. First, the complete eg1 gene (named Feg1) was PCR amplified from $T$. reesei AS3.3711 genomic DNA using P1 and P2. Second, exon 1 in Feg1 was obtained using gene splicing by overlap extension PCR (SOE-PCR) with P1 and P3 as the primers. Exon $2+3$ was amplified by SOE-PCR using P4 and P5, and exon $1+2+3$ was amplified by SOE-PCR using P1 and P5. Exon $1+2+3$, which lacks two introns, additionally contained the signal peptide sequence from the FTeg1 gene. Exon $1+2+3$ was subsequently cloned into the pMD-18T vector (Takara, Japan) and confirmed by sequencing. This plasmid was named pMD-exon $1+2+3$. Finally, the no-signal peptide sequence named Neg1 was amplified from the plasmid pMD-exon $1+2+3$ by PCR using P1 and P8 (EcoRI and BamHI sites are underlined). The Neg1 gene was cloned into the expression vector $\mathrm{pYE} \alpha$, which contained the $\alpha$-factor promoter. The coding region for the $\alpha$-factor signal was amplified by PCR using the PPIC9K vector (Invitrogen Corporation, Carlsbad, CA) as a template, which carries the $\alpha$ factor secretion signal to target recombinant proteins to the growth medium. ${ }^{33}$ The construction methods for the expression plasmids derived from T. pseudokoningii and T. longibrachiatum were the same as those used for $T$. reesei. In summary, we obtained the expression plasmids pYE $\alpha$-NTeg1 (from T. reesei), pYE $\alpha$-NPeg1 (from T. pseudokoningii), and pYE $\alpha$-NLeg1 (from $T$. longibrachiatum).

\subsection{DNA shuffling}

DNA shuffling is a method for the in vitro homologous recombination of selected mutant genes by random fragmentation and PCR reassembly. To screen for a highly active EGI, we used

Table 2 PCR primers used in this study for the cloning and sequencing

\begin{tabular}{|c|c|c|}
\hline Primer name & Sequence $\left(5^{\prime}-3^{\prime}\right)$ & Restricti \\
\hline \multicolumn{3}{|l|}{ eg1 (T. ressei) } \\
\hline $\mathrm{P} 1$ & TGGAATTCATGGCGCCCTCAGTTACACTGC & EcoRI \\
\hline $\mathrm{P} 2$ & GCGGATCCCTAAAGGCATTGCGAGTAGTC & BamHI \\
\hline P3 & TCCGGGGCCGTAGTAGCTTTTGTAGCCGCTGC & \\
\hline $\mathrm{P} 4$ & GCAGCGGCTACAAAAGCTACTACGGCCCCGGA & \\
\hline P5 & GGCAAGCTTCTAAAGGCATTGCGAGTAGTAGTCGTTGCTATACTG & HindIII \\
\hline P7 & TTGAATTCCAGCAACCGGGTACCAGCAC & Eco RI \\
\hline P8 & GCGGATCCCAGCAACCGGGTACCAGCAC & BamHI \\
\hline \multicolumn{3}{|c|}{ eg1 (T. pseudokoningii and T. longibrachiatum) } \\
\hline LP1 & TAGAATTCATGGCGCCCTCAGCTACACTGC & EcoRI \\
\hline LP2 & GCGGATCCCTAGAGGCATTGCGAGTAGT & Bam HI \\
\hline LP3 & TCCGGGGCCGAAGTAGTTCGGGTAGCCGCTGC & \\
\hline LP4 & GCAGCGGCTACCCGAACTACTTCGGCCCCGGA & \\
\hline PP5 & CTAGAGGCATTGCGAGTAGTAATCATTGCCATACTG & \\
\hline PP6 & TAGAATTCCAGCAACCGGGCACCAGCAC & $E c o$ RI \\
\hline
\end{tabular}

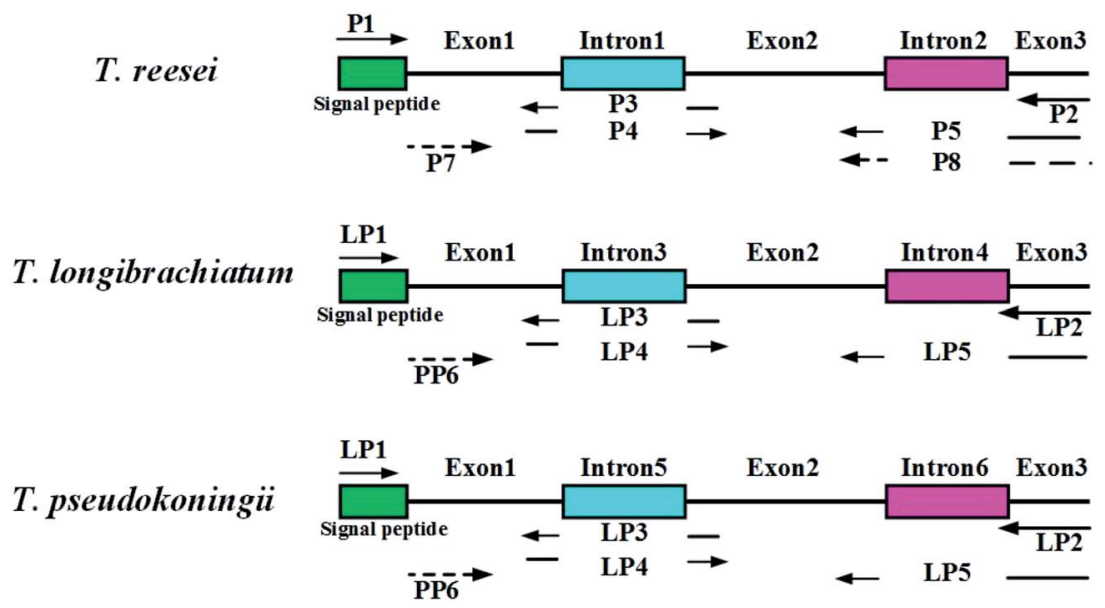

Fig. 1 Construction of endoglucanase I (EGI) mature peptide of three wild type Trichoderma sp. Two introns and one signal peptide of eg1 gene were removed by SOE-PCR. 
DNA shuffling generated by a modified method found in the literature. $^{34}$ The recombinant plasmids pYE $\alpha$-NTeg1, pYE $\alpha$ NPeg1, and pYE $\alpha$-NLeg1 were used as templates to amplify the Neg1 fragments separately with the primers P7/P8, PP6/LP2, and PP6/LP2, respectively. Following purification, $8 \mu \mathrm{g}$ of the three PCR products were mixed and randomly fragmented by DNaseI for $5 \mathrm{~min}$ at $16{ }^{\circ} \mathrm{C}$. The purified fragments of 50-100 bp were used in primerless PCR reactions to reassemble into full-length genes using the following the program: $90 \mathrm{~s}$ at $96{ }^{\circ} \mathrm{C} ; 35$ cycles of $94{ }^{\circ} \mathrm{C}$ for $30 \mathrm{~s}, 65-0.7{ }^{\circ} \mathrm{C}$ per cycle for $90 \mathrm{~s}, 90 \mathrm{~s}+3 \mathrm{~s}$ per cycle at $72{ }^{\circ} \mathrm{C}$; and $10 \mathrm{~min}$ at $72{ }^{\circ} \mathrm{C}$. The reassembled genes of the correct size were obtained by using the primerless PCR reaction products (1/10 dilution) as template with P7/P8 and PP6/LP2 as specific primers. ${ }^{35}$ The program for the PCR reactions with primers was as follows: $94{ }^{\circ} \mathrm{C}$ for $2 \mathrm{~min} ; 25$ cycles of $30 \mathrm{~s}$ at $94{ }^{\circ} \mathrm{C}$, $55 \mathrm{~s}$ at $45{ }^{\circ} \mathrm{C}, 90 \mathrm{~s}$ at $72{ }^{\circ} \mathrm{C}$; and $72{ }^{\circ} \mathrm{C}$ for $5 \mathrm{~min}$. The resulting recombinants were transformed into $S$. cerevisiae INVSc1 (Mat $\alpha$, his3- $\Delta 1$, leu2, trp1-289, ura3-52; Invitrogen) competent cells to screen for the evolved mutants.

\subsection{Yeast transformation}

Saccharomyces cerevisiae INVSc1 cells were grown in YPDgalactose prior to transformation, then plated directly onto SC medium containing galactose and lacking uracil (SC-U-GL) to select for transformants. ${ }^{36}$ The three purified wild-type Neg1 genes and the primer PCR reaction product Seg1 from the DNA shuffling were digested with BamHI and EcoRI and ligated into the pYE $\alpha$ expression vector that had been digested with the same enzymes. The pYE $\alpha$ plasmid contains the ampicillin resistance gene (for selection in E. coli) and URA3 (for uracil prototrophy selection in INVSc1 cells), with expression of the target gene controlled by the GAL1 promoter and induced by galactose. The recombinant plasmids were transformed into the $S$. cerevisiae INVSc1 cells using the lithium acetate/DMSO method described by Hill et $a .^{37}$ The transformants were selected for growth on SC-U-GL plates.

\subsection{Screening EGI mutants with improved activities by Congo red staining method}

The transformed clones containing the wild EGI genes and mutated EG I genes were picked up and spotted on the SC-UCMC-G plates [SC-U-GA with $1 \%$ carboxymethyl cellulose (CMC), D-galactose and $2 \%$ agar]. After incubation at $30{ }^{\circ} \mathrm{C}$ for $72 \mathrm{~h}$, the plates were stained with $0.1 \%$ Congo red (Amresco, USA) solution for $30 \mathrm{~min}$. The Congo red solution was poured off and the plates were rinsed with $1 \mathrm{M}$ of $\mathrm{NaCl}$ for $30 \mathrm{~min}$ for the sake of displaying the halos generated from the hydrolysis of the CMC substrate in the plates by the all EGI wild types and variants. ${ }^{29}$ The EGI variants showing the larger halos than that of the wild types was chosen for the further research.

\subsection{Characterization of EGI and its variant SEGI $_{8}$}

The carboxymethyl cellulase (CMCase) activities of the three EGIs and $\mathrm{SEGI}_{8}$ were determined by measuring the amount of glucose released from carboxymethyl cellulose sodium
(CMC-Na) using the 3,5-dinitrosalicylic acid (DNS) method with glucose as a standard. ${ }^{38}$ The reaction mixtures contained $2 \mathrm{~mL}$ of $10 \mathrm{~g} \mathrm{~L}^{-1} \mathrm{CMC}-\mathrm{Na}$ in $0.05 \mathrm{M}$ citrate buffer (pH 4.8) and $1 \mathrm{~mL}$ of each enzyme solution appropriately diluted with the same buffer. As a control, an aliquot of each diluted enzyme solution was first heat-inactivated in a boiling-water bath for $5 \mathrm{~min}$. After a short incubation at $50{ }^{\circ} \mathrm{C}$ for $10 \mathrm{~min}$, the control reactions were terminated by adding $1.5 \mathrm{~mL}$ of DNS, while the sample reactions were incubated at $50{ }^{\circ} \mathrm{C}$ for $1 \mathrm{~h}$ before being terminated. All of the sample mixtures were also heat-inactivated by mixing well and incubating in a boiling-water bath for $5 \mathrm{~min}$ before cooling to room temperature. A microplate reader (BioTeck, HTX, USA) was used to measure the absorbance of the reaction solutions at $540 \mathrm{~nm}$.

The International Unit (IU) of activity is defined as the amount of enzyme that liberates $1 \mu \mathrm{mol}$ of glucose per minute in a standard assay. ${ }^{39}$ The optimum culture times for NTEGI (protein encoded by Neg1 genes), NLEGI (protein encoded by Leg1 genes), NPEGI (protein encoded by Peg1 genes), and SEGI were determined by measuring the IU of CMCase activity at different culture times (48-168 h) with CMC-Na. The optimal working temperatures for NTEGI, NLEGI, NPEGI, and $\mathrm{SEGI}_{8}$ were determined by evaluating their activities at temperatures ranging from $30{ }^{\circ} \mathrm{C}$ to $70{ }^{\circ} \mathrm{C}$. The optimal working pHs for NTEGI, NLEGI, NPEGI, and $\mathrm{SEGI}_{8}$ were determined by evaluating their maximal activities in buffer conditions $\left(\mathrm{Na}_{2} \mathrm{HPO}_{4}-\right.$ $\mathrm{NaH}_{2} \mathrm{PO}_{4}$ ) ranging from $\mathrm{pH} 3.2$ to 6.6.

\subsection{Sequence analysis}

Phyre 2.0 server (http://www.sbg.bio.ic.ac.uk/phyre) was employed to create the homology model of $\mathrm{SEGI}_{8}$ using NTEGI structure (PDB code: 1EG1) as a template. ${ }^{\mathbf{4 0}}$ Multiple protein sequence alignment was performed using Clustal $\mathrm{X}^{\mathbf{4 1}}$ and ESPript 3.0 web tool (http://espript.ibcp.fr/ESPript/cgi-bin/ ESPript.cgi). Structure visualization and analysis were achieved by using the PyMOL (http://www.pymol.org/). ${ }^{42}$

\section{Results}

\subsection{Cloning and sequence analysis of the wild type eg1}

The complete eg1 genes (FTeg1, FLeg1, and FPeg1) were amplified by using genomic DNA as the template. The FTeg1, FLeg1, and FPeg1 fragments contained 1507 bp, 1566 bp, and 1566 bp, respectively. Based on a sequence homology analysis conducted with the ClustalW program, FTeg1 showed very high identities with FLeg1 (90\%) and FPeg1 (90\%). ${ }^{43,46}$ Specifically, FLeg1 had a very high similarity to FPeg1 (99\%). Following SOE-PCR, exon $1+2+3$ fragments (mature peptide) from FTeg1, FLeg1, and FPeg1 (1380 bp in FTeg1, 1386 bp in FLeg1, and 1386 bp in FPeg1) were obtained (Table 3, Fig. 1). None of the single peptide sequences (NTeg1, NLeg1 and NPeg1) amplified from the three exon $1+2+3$ fragments contained 1314 bp, $1320 \mathrm{bp}$, or $1320 \mathrm{bp}$, respectively. 
Table 3 Cleavage of signal peptide sequences and introns in eg1

\begin{tabular}{|c|c|c|c|}
\hline Kinds of Trichoderma sp. & Primers & DNA fragment for PCR & Description \\
\hline \multirow{4}{*}{ T. reesei } & $\mathrm{P} 1 / \mathrm{P} 2$ & $1507 \mathrm{bp}$ full sequence & FTeg1 \\
\hline & $\mathrm{P} 1 / \mathrm{P} 3$ & $770 \mathrm{bp}$ exon 1 & \\
\hline & P1/P5 & $1380 \mathrm{bp}$ exon $1+2+3$ & \\
\hline & $\mathrm{P} 7 / \mathrm{P} 8$ & No signal peptide sequence & NTeg1 \\
\hline \multirow[t]{3}{*}{ T. longibrachiatum } & LP1/LP2 & 1566 bp full sequence & FLeg1 \\
\hline & LP1/LP5 & 1386 bp exon $1+2+3$ & \\
\hline & PP6/LP2 & No signal peptide sequence & NLeg1 \\
\hline \multirow[t]{4}{*}{ T. pseudokoningii } & LP1/LP2 & $1566 \mathrm{bp}$ full sequence & FPeg1 \\
\hline & LP1/LP3 & 770 bp exon 1 & \\
\hline & LP4/LP5 & 616 bp exon $2+3$ & \\
\hline & LP1/LP5 & 1386 bp exon $1+2+3$ & \\
\hline
\end{tabular}

\subsection{DNA shuffling and screening variants with the most improved activities by Congo red staining}

We used the Congo red staining method to screen EGI variants expressed from the mutated eg1 gene library that was generated to improve activity. After screening approximately 1000 transformants, 8 were found to have considerably larger halos than the EGI wild types (data not shown). The protein variants expressed by these transformants were considered to have improved activities compared to the three wild types, NTEGI, NLEGI and NPEGI. One protein variant, $\mathrm{SEGI}_{8}$, repeatedly produced larger halos than the other transformants and wild-type EGIs in multiple tests, and it was chosen for further analysis (Fig. 2).

\subsection{Sequence analysis of $\mathrm{SEGI}_{8}$}

Based on the sequence homology analysis, $\mathrm{SEGI}_{8}$ was assigned to glycosyl hydrolase family 7 , showing very high identities with the EGIs from T. reesei (95\%, NTEGI), T. longibrachiatum (96\%, NLEGI), and $T$. pseudokoningii (97\%, NPEGI). ${ }^{44}$ The multiple sequence alignment was performed using the ClustalX program and ESPript 3.0 (Fig. 3). The results showed that $\mathrm{SEGI}_{8}$ had four residues with point mutations that caused amino acid substitutions, with Ala10, Ser100, Lys192, and Gly318 substituting for the Val10, Gly100, Phe192, and Ser318, respectively, present in the three wild type EGIs (marked with yellow background). V10A and F192L did not change the hydrophobicity, while G100S and

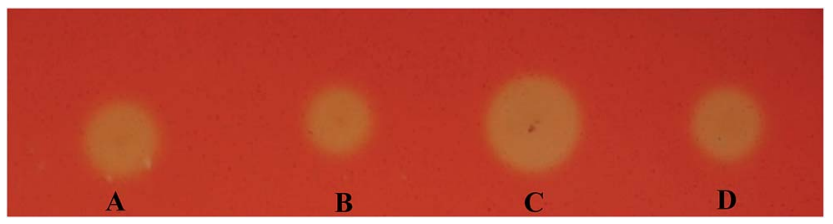

Fig. 2 Halos formed by variants with improved activities detected by Congo red staining assay. (A) INVSc1 harboring the plasmid $p Y E \alpha-$ NLeg1 transformants; (B) INVSc1 harboring the plasmid pYE $\alpha$-Nlegl transformants; (C) INVSC1 harboring the plasmid pYE $\alpha$-Segl8 transformants; (D) INVSc1 harboring the plasmid pYE $\alpha$-NPegl transformants.
S318G changed the hydrophilicity. In addition, $\mathrm{SEGI}_{8}$ had 19 residues (including the four residues with point mutations) that differed from those in NTEGI (PDB Code: 1EGI), which are shadowed with white. ${ }^{45}$ Sixteen active-site residues are labeled with pink asterisks. ${ }^{8}$

\subsection{Analysis of EGI enzymatic activity}

The enzyme activities of NTEGI, NPEGI, NLEGI, and $\mathrm{SEGI}_{8}$ are shown in Fig. 4. All four EGIs had maximal activity at $\mathrm{pH}$ 5.6. The activity levels of these four EGIs increased from $\mathrm{pH} 3.3$ to pH 5.6 and then rapidly decreased from $\mathrm{pH} 5.6$ to $\mathrm{pH}$ 6.0. However, the activity levels of NLEGI and $\mathrm{SEGI}_{8}$ increased again from $\mathrm{pH} 6.0$ to $\mathrm{pH}$ 6.6, although they were less than that at $\mathrm{pH}$ 5.6. NTEGI, NPEGI, NLEGI, and $\mathrm{SEGI}_{8}$ exhibited activity at temperatures ranging from $30{ }^{\circ} \mathrm{C}$ to $50{ }^{\circ} \mathrm{C}$ as shown in Fig. $4 \mathrm{~B}$, with optimal activities at $50{ }^{\circ} \mathrm{C}$. Additionally, the activity levels of the four EGIs increased from $30{ }^{\circ} \mathrm{C}$ to $50{ }^{\circ} \mathrm{C}$, decreased from $50{ }^{\circ} \mathrm{C}$ to $60{ }^{\circ} \mathrm{C}$, and weakly increased again from $60{ }^{\circ} \mathrm{C}$ to $70{ }^{\circ} \mathrm{C}$. Importantly, $\mathrm{SEGI}_{8}$ showed a higher activity level than the wildtype NEGIs at all times. As shown in Fig. 4C, NLEGI, NTEGI, and $\mathrm{SEGI}_{8}$ reached their maximal activity levels at $96 \mathrm{~h}$, while the activity of NPEGI was at a maximum at $72 \mathrm{~h}$. The extracellular enzyme activity of $\mathrm{SEGI}_{8}$ approached its highest level of $1.97 \mathrm{U}$ $\mathrm{mL}^{-1}$ when cultured for $96 \mathrm{~h}$, which is about 1.9 times higher than the average of the three wild-type NEGIs. Specifically, $\mathrm{SEGI}_{8}$ showed 1.99-fold, 2.22-fold, and 1.69-fold increases in activity over NTEGI, NPEGI, and NLEGI, respectively.

\subsection{D structural modeling analysis}

The relative locations of the substituted amino acid residues could be located in the modeled 3D structure (Fig. 5). The predicted structure of $\mathrm{SEGI}_{8}$ (colored brown) was similar to that of NTEGI (colored green; PDB code: 1EGI). After alignment, the position of three residues, the substitutions V10A, G100S, and F192L, were located in three different loop regions on the surface of $\mathrm{SEGI}_{8}$. Substitution $\mathrm{S} 318 \mathrm{G}$ was positioned in a center $\beta$-sheet, which was located in the $\beta$-sandwich core. Importantly, a comparison of the $\beta$-sandwich cores of NTEGI and $\mathrm{SEGI}_{8}$ 

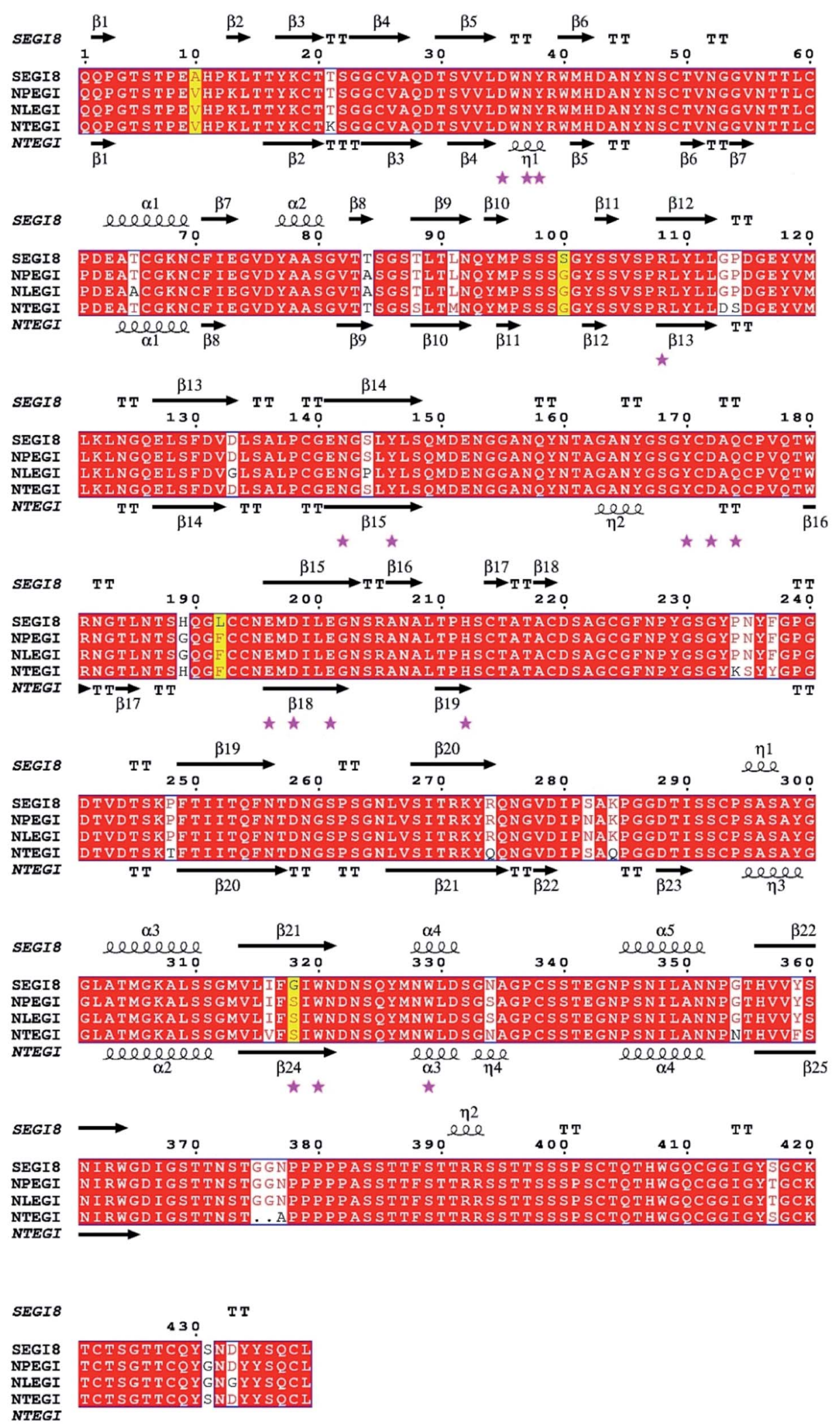

Fig. 3 Multiple sequence alignment of EGI with similar endoglucanases between $\mathrm{SEGl}_{8}$ and three wild types. The red letters in yellow background indicate four point mutant residues (V10A/G100S/F192L/S318G). Partial different residues were shaded in white background. The white letters in white boxes indicate similarity. The active-site referring to $T$. reesei are indicated by pink pentagrams $(\star)$. The multiple sequence alignment was performed using ClustalX program and ESPript 3.0 (http://www.espript.ibcp.fr). 

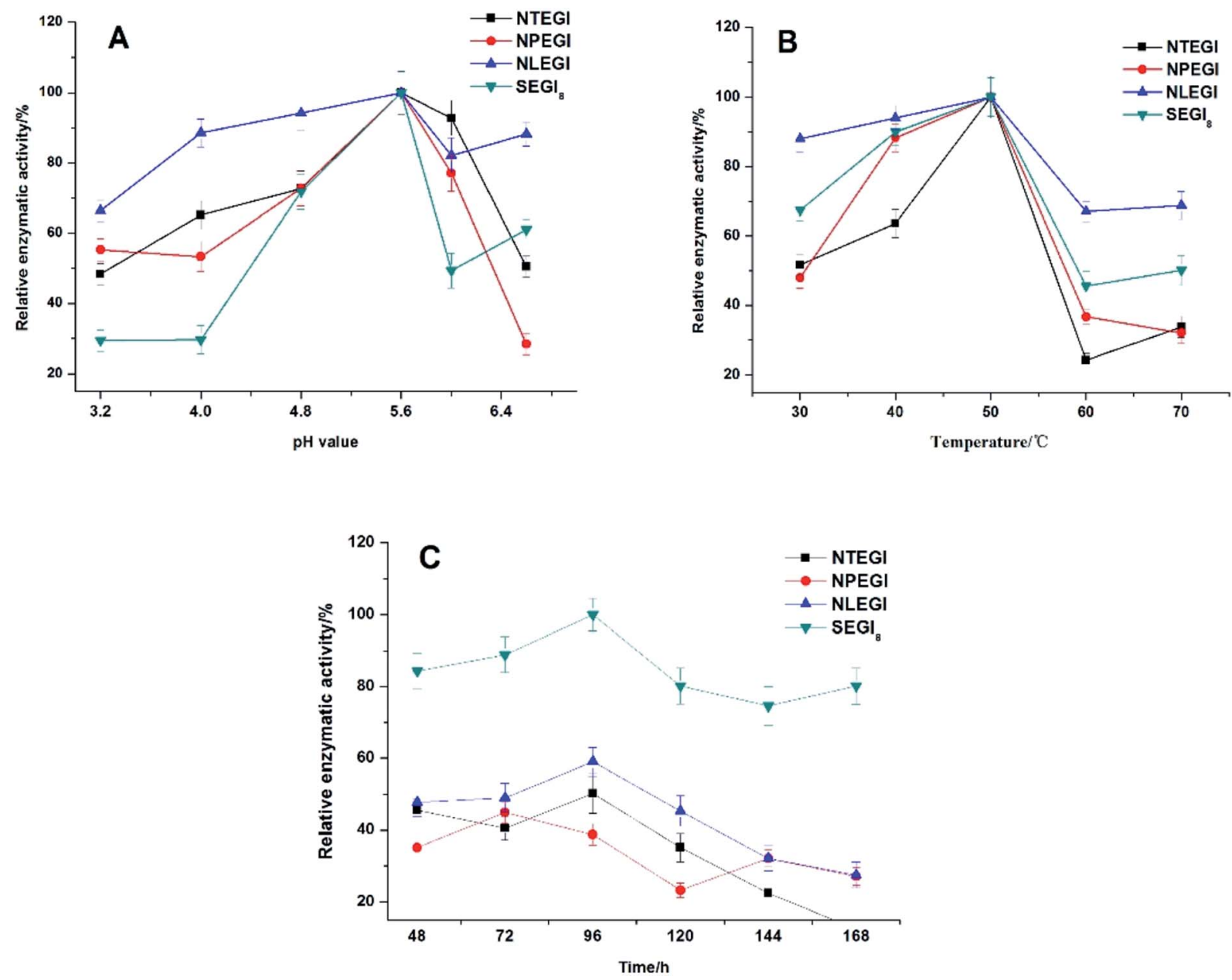

Fig. 4 Effect of $\mathrm{pH}$, temperature and time on enzyme activity. (A) Effect of $\mathrm{pH}$ value on enzyme activity. Enzyme activity was measured in the different buffers with $\mathrm{pH}$ ranging from 3.2 to 6.6 at $50{ }^{\circ} \mathrm{C}$ for $120 \mathrm{~min}$. The maximum activity observed was taken as $100 \%$. (B) Effect of temperature on enzyme activity. The reaction was carried out at the temperatures ranging from $30^{\circ} \mathrm{C}$ to $70^{\circ} \mathrm{C}$. The maximum activity observed was taken as $100 \%$. (C) Effect of time on enzyme stability. The samples was measured at different times ranging from $48 \mathrm{~h}$ to $168 \mathrm{~h}$ at $50{ }^{\circ} \mathrm{C}$. The maximum activity observed was taken as $100 \%$. Error bars represent the means and standard deviations based on three replicates.

revealed that they have different substrate-binding grooves, with both proteins having their active site located in an open cleft (red color in NTEGI and from $194 \mathrm{C}$ to $207 \mathrm{~N}$ in $\mathrm{SEGI}_{8}$ ). However, the major structure of the active site in $\mathrm{SEGI}_{8}$ was a loop region, while the same location was a $\beta$-sandwich in NTEGI. Moreover, a similar change occurred at the bottom of the substrate-binding grooves (purple color in NTEGI and from $207 \mathrm{~N}$ to $211 \mathrm{P}$ in $\mathrm{SEGI}_{8}$ ). Another obvious difference between the models for $\mathrm{SEGI}_{8}$ and NTEGI was the predicted structure of a flexible linker region and a CBD (blue color in $\mathrm{SEGI}_{8}$ ).

\section{Discussion}

In this study, we succeeded in constructing a secretory expression system for whole EGI protein in $S$. cerevisiae INVSc1 and directed the evolution of eg1 genes from three wild type Trichoderma spp. by DNA shuffling. One protein variant $\left(\mathrm{SEGI}_{8}\right)$ was screened out that had approximately $169 \%$ to $257 \%$ increased enzymatic activity in comparison to the wild types. The locations of four point mutations (V10A, G100S, F192L, and
$\mathrm{S} 318 \mathrm{G})$ in $\mathrm{SEGI}_{8}$ were identified through a 3D structural modeling analysis, which found that the $\beta$-helix in NTEGI was transformed into a loop region in $\mathrm{SEGI}_{8}$. This novel assay overcame the limitations of other cellulase expression systems and common molecular methods, ${ }^{\mathbf{2 9 , 3 0 , 4 6}}$ and it could be widely applied to different cellulases. Therefore, it could serve as a reliable system to degrade cellulose and be utilized in bioenergy production.

The new method proposed in this system includes a new and extremely efficient technique for screening cellulases. Although previous studies have demonstrated that fungal endoglucanases are important for the biomass degradation of lignocellulose, display synergistic effects with cellobiohydrolases and $\beta$ 1,4-glucosidase during enzymatic hydrolysis, ${ }^{47}$ and that many endoglucanase genes can be expressed in $E$. coli, the new approach in this study was performed by eukaryotic expression in $S$. cerevisiae..$^{22,30,48,49}$ It is known that the EGI CD is joined to the CBD by an extended $O$-glycosylated interdomain-linker peptide with an abundant serine/threonine-rich hinge. ${ }^{3}$ But no structure has been determined for an intact multi-domain 

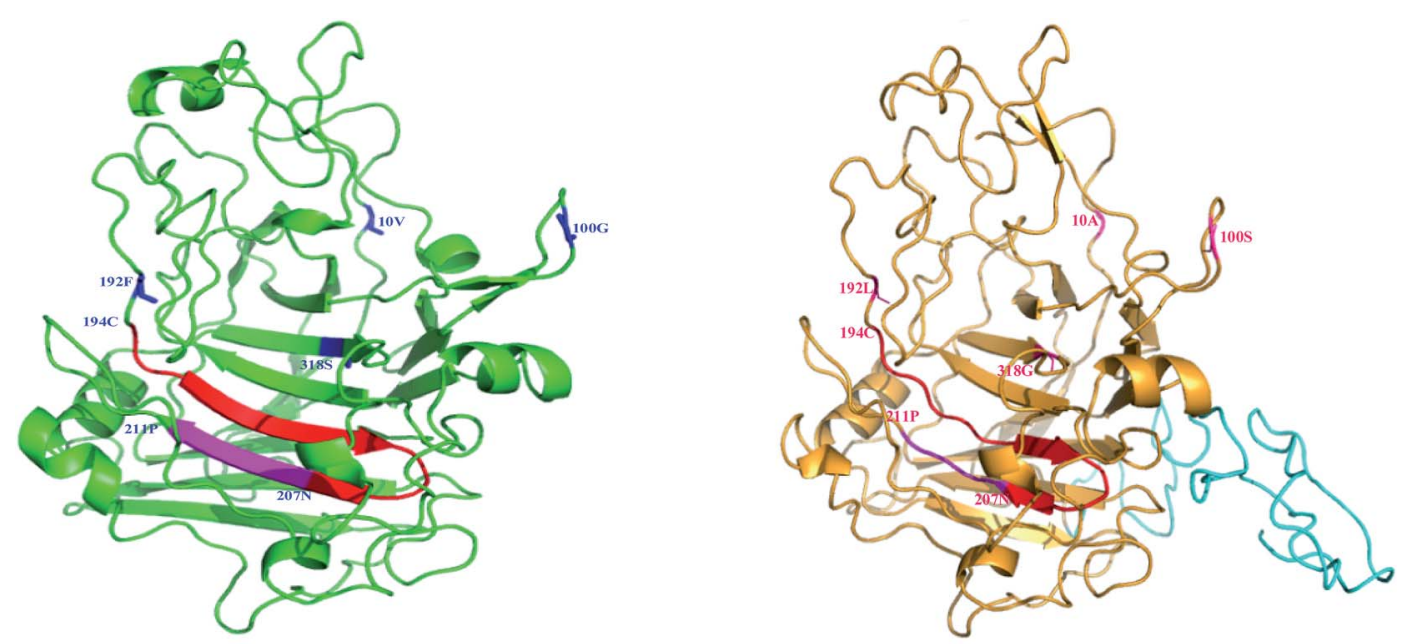

A

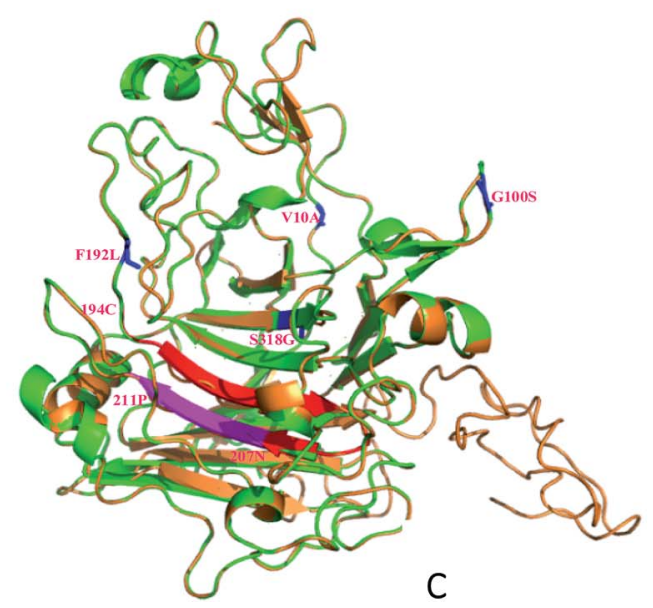

B

Fig. 5 Three-dimensional modelling of EGI in T. reesei and SEGI 8 . (A) Modeling structure of NTEGI, (B) modeling structure of SEGl 8 , (C) alignment of two modeling structures. Modeling structure of $\mathrm{SEGl}_{8}$ and NTEGl, highlighted according to different segments of secondary structure. The red part in four point mutations represented carbonyl and hydroxyl. The blue and pink parts represented amidogen and $\mathrm{C}^{\alpha}$ backbone.

EGI, which consists of the catalytic core, linker, and CBD. ${ }^{50}$ Although EGI was expressed in E. coli, the expression product of the inclusion body could not be obtained due to the $O$-glycosylated interdomain-linker peptide and $N$-glycosylations in the asymmetric unit. A previous study showed that the EGI CD obtained from $T$. reesei contained a truncated eg1 gene (residues 1 to 371)..$^{51}$ This was provided to us by E. Margolles-Clark et al. The CBD from $T$. reesei is necessary to efficiently attach to crystalline cellulose and facilitates the breakdown of the crystalline structure. ${ }^{52}$ Therefore, segmentation expression and evolving EGI are not conducive to understanding the whole protein function. Our eukaryotic expression in S. cerevisiae provided a feasible method for understanding the function of the whole mature EGI peptide. In addition, we expressed the eg1 gene from three Trichoderma spp. in yeast under the control of the prepro $\alpha$-factor secretion signal sequence. ${ }^{44,53}$ This $\alpha$-factor will be helpful in studying secreted proteins as well as for elucidating the mechanisms involved in producing extracellular expression. ${ }^{54}$ In practice, it is convenient to directly observe the behavior by means of the EGI enzyme, and in our study, $\alpha$-factor allowed $S$. cerevisiae INVSc1 to secrete it extracellularly.
During the process of DNA shuffling, we constructed a large library (about $7 \times 10^{3}$ ) because we used the primer PCR reaction products and the yeast expression vector pYE $\alpha$ to directly transform S. cerevisiae (data not shown). In our previous work, we used two other methods to construct the library. One of the methods we used previously is to ligate the PCR products to the pMD-19T vector and transform E. coli. After digestion of the recombinant plasmid, the target fragment was ligated to the pYE $\alpha$ vector in the transformation of yeast. The other method is to ligate PCR products to the pYE $\alpha$ vector and transform $E$. coli, similar to the process of Plessis et al. ${ }^{30}$ Although we can obtain many positive transformants by using these two methods, the results appear to indicate that the number of identical transformants and the screening process need more work. Therefore, the new gene was amplified with the colony PCR method from the efficient transformants that were obtained by screening clones. Additionally, this method results in a low repetition rate of the transformants but few libraries, which could improve the successful probability of screening a highly activity enzyme. However, we increased the enzyme activity slightly because we wanted to use one round of DNA shuffling. Subsequently, we 
focused on optimizing the process of DNA shuffling and using several rounds of DNA shuffling or error-prone PCR to screen for the better mutant.

We demonstrated the improved activity of $\mathrm{SEGI}_{8}$ with $\mathrm{CMC} /$ Congo-red plate assays. To understand how the changed amino acid residues in $\mathrm{SEGI}_{8}$ contributed to the improved activity, the structure of a 3D model of $\mathrm{SEGI}_{8}$ was predicted using Phyre 2.0 using $S$. cerevisiae as the template, because it has a hydrolase showing $95 \%$ identity with the NTEGI amino acid sequence..$^{55,56}$ We found that the change of amino acid Ser318 into Gly closed the active site located on the $\beta$-sheet of the sandwich core in the $\mathrm{SEGI}_{8}$ variant. Obviously, the $\beta$-sheet in the sandwich core of $\mathrm{SEGI}_{8}$ was shorter than that of NTEGI (Fig. 5C). According to previous research, glycine residues may provide more flexibility than other amino acids, which is necessary for enzyme active sites (such as position 318 ) to change conformation. ${ }^{57}$ For the catalytic event, the chain remains trapped inside the active-site tunnel of the endoglucanases. The loops closest to the active site were essential in the EGI structures. As shown in Fig. 5, the $3 \mathrm{D}$ modeling of the active-site tunnel in $\mathrm{SEGI}_{8}$ (colored red) was different from that in NTEGI (colored blue), which has been previously analyzed in a study performed by G. J. Kleywegt..$^{55}$ The change in the loop regions in $\mathrm{SEGI}_{8}$ may enlarge the substrate-binding space. It is possible that S318G affects the substrate binding and contributes to the improved activity of $\mathrm{SEGI}_{8}$. The same change occurred with residues $208 \mathrm{~A}$ to $212 \mathrm{H}$ (colored purple) in $\mathrm{SEGI}_{8}$. This might explain how the amino acid change could extend the capacity for substrate binding to the active center of the sandwich structure, and therefore lead to the 1.99-fold improved activity. ${ }^{55,58}$ In addition, as indicated by the structure of the $\mathrm{SEGI}_{8}$ model, position Leu192 before the active-site residues from Glu194 to Asn207 in EGI is involved in substrate binding. ${ }^{55}$ Therefore, the leucine amino acid, which lacks a benzene ring, might change the backbone configuration of the $\beta$-sheet in the sandwich core.

$\mathrm{SEGI}_{8}$ displayed the important characteristic of enzymatic stability, because the conformational changes influenced both its thermo- and pH stability. Much work has been done on the mechanism for alkalinity tolerance with the alkaline cellulase produced by bacteria. ${ }^{59}$ The pH stability of NLEGI and $\mathrm{SEGI}_{8}$ in the 5.6 to 6.6 range was related to the two alterations at $144 \mathrm{P}$ and 100 S, respectively. Previous reports suggest that the introduction of proline provided stability at physiological $\mathrm{pH}$, and then the serine modified the proline residue. ${ }^{28,60}$ This was the most effective single substitution to enhance CMCase activity. ${ }^{28}$ In other research, a mutation-guided approach for improving thermostability was used to engineer variants of endoglucanase I (Cel7B) from four EGIs that are able to hydrolyze cellulosic substrates at temperatures ranging from $50-70{ }^{\circ} \mathrm{C}$, as shown in Fig. 4B. Chokhawala indicated that the B-factors grouped at seven sites [site A (aa 284-287), site B (aa 301-302), site C (aa 113, 115), site D (aa 238), site E (aa 230), site F (aa 323), site G (aa 291)] were chosen for site-saturation mutagenesis, and that it could improve the thermostability of EGI ${ }^{56}$ In our study, sites A, C, and D in NLEGI, NPEGI, and $\mathrm{SEGI}_{8}$ were all different from the NTEGI control. This may be one of the reasons for the increased activity. Moreover, the glycosylation of NTEGI enzymes renders them more thermostable, which is consistent with other reports showing the importance of glycosylation in protein thermostability. The cyclization of N-terminal glutamine to a pyroglutamate in $S$. cerevisiae expressing NTEGI resulted in more thermostability. ${ }^{61,62}$ The S318G mutation and nearby N321T have a similar structure-activity relationship in SEGI 8 . Hikaru Nakazawa also indicated that changes in the activity center could increase thermo- and $\mathrm{pH}$ stability. ${ }^{28}$

In summary, we used DNA shuffling to screen for mutants with higher activity, thermo-stability, and $\mathrm{pH}$ stability, and found one, $\mathrm{SEGI}_{8}$, that we characterized. The $3 \mathrm{D}$ modeling of the $O-$ glycosylated flexible linker region and CBD (residues 372 to 439) were predicted by using PyMOL (Fig. 5). These two regions were shown with strips of loop, which is important for substrate binding. ${ }^{55}$ Further research is needed to confirm whether the loops in the linker and CBD regions affect the activity of $\mathrm{SEGI}_{8}$.

Furthermore, it should be pointed out that there were two amino acid residues (M91L and F359Y) of $\mathrm{SEGI}_{8}$ different from NTEGI, which were highly conserved across the glycoside hydrolase family 7 as shown by multiple sequence alignment. ${ }^{55}$ In the future, we will devote to research whether charge of these conserved amino acids in other endoglucanase could result in the improved activities.

\section{Conclusion}

In summary, a library of mutant endoglucanase EGI from three mixed Trichoderma sp. was constructed using DNA shuffling, and one mutants $\mathrm{SEGI}_{8}$ promoting the enzyme activity was obtained using screening by $\mathrm{CMC} /$ Congo-red plate assays among approximately 1000 variants. The variant $\mathrm{SEGI}_{8}$ were found to show 1.99 , 2.22 and 1.69 fold improved activities compared to T. reesei, $T$. pseudokoningii and T. longibrachiatum, respectively. Although improved activities were observed, the $\mathrm{SEGI}_{8}$ variants showed very similar $\mathrm{pH}$ and temperature with three wild type strain, which could be a better choice to apply in the same industrial condition. Mutant $\mathrm{SEGI}_{8}$ produced by the clone showed broad $\mathrm{pH}$ stability (5.6-6.6), while performed the similar thermotolerance $\left(60-70{ }^{\circ} \mathrm{C}\right)$ compared with three wild-type EGIs. Based on the sequence analysis, it was found that $\mathrm{SEGI}_{8}$ had four point mutants, with the residues Ala10, Ser100, Leu192 and Gly318 respectively substituting the residues Val10, Gly100, Phe192 and Ser318 in NTEGI. Through 3D-structural modelling, the major structure of active site in $\mathrm{SEGI}_{8}$ was loop regions while the same location was $\beta$-helix in NTEGI. It was suggested the substitution Ser318 in SEGI $_{8}$ might directly affect the substrate binding and activity-site, and therefore contribute to their improved activities. In all, we have demonstrated that DNA shuffling can be applied to improve the activities of enzymes from glycoside hydrolase family 7 , which should provide available information for engineering of all endoglucanases from this family.

\section{Conflicts of interest}

The authors declare that the research was conducted in the absence of any commercial or financial relationships that could be construed as a potential conflict of interest. 


\section{Acknowledgements}

This research was financially supported by the Key project of Natural Science Research of Anhui Provincial Education Department (KJ2009A75), Science and Technology Commission of Shanghai Municipality (14DZ1205100, 14320502100), Key Project of Shanghai Agriculture Prosperity through Science and Technology (Grant: 2017, 4-4), the "Dawn" Program of Shanghai Education Commission (15SG48), and Shanghai Engineering Research Center of Aquatic-Product Processing \& Preservation. This work was also supported by the program granted by Funding program for outstanding dissertations of Shanghai Ocean University.

\section{References}

1 S. B. Leschine, Annu. Rev. Microbiol., 1995, 49, 399-426.

2 R. Kumar, S. Singh and O. V. Singh, J. Ind. Microbiol. Biotechnol., 2008, 35, 377-391.

3 M. Claeyssens, T. H. Van, P. Tomme, T. M. Wood and S. I. Mcrae, Biochem. J., 1989, 261, 819-825.

4 P. Béguin and J. P. Aubert, FEMS Microbiol. Rev., 1994, 13, $25-$ 58.

5 J. R. Cherry and A. L. Fidantsef, Curr. Opin. Biotechnol., 2003, 14, 438-443.

6 E. A. Bayer, H. Chanzy, R. Lamed and Y. Shoham, Curr. Opin. Struct. Biol., 1998, 8, 548-557.

7 M. Anbar, R. Lamed and E. A. Bayer, Chemcatchem, 2010, 2, 997-1003.

8 M. Penttilä, P. Lehtovaara, H. Nevalainen, R. Bhikhabhai and J. Knowles, Gene, 1986, 45, 253-263.

9 S. J. Horn, G. Vaajekolstad, B. Westereng and V. G. H. Eijsink, Biotechnol. Biofuels, 2012, 5, 89-93.

10 B. Henrissat, Biochem. J., 1991, 293(Pt 3), 781-788.

11 B. Henrissat and A. Bairoch, Biochem. J., 1993, 293(Pt 3), 781788.

12 J. Kolbe and C. P. Kubicek, Appl. Microbiol. Biotechnol., 1990, 34, 26-30.

13 H. J. Gilbert and G. P. Hazlewood, J. Gen. Microbiol., 1993, 139, 187-194.

14 H. Watanabe and G. Tokuda, Cell. Mol. Life Sci., 2001, 58, 1167-1178.

15 H. Watanabe and G. Tokuda, Annu. Rev. Entomol., 2010, 55, 609-632.

16 S. Zhang, Q. Y. Yin, Y. H. Li, M. Ding, G. J. Xu and F. K. Zhao, Appl. Microbiol. Biotechnol., 2007, 75, 1327-1334.

17 H. Watanabe, H. Noda, G. Tokuda and N. Lo, Nature, 1998, 394, 330-331.

18 M. Sugimura, H. Watanabe, N. Lo and H. Saito, Eur. J. Biochem., 2003, 270, 3455-3460.

19 D. Sternberg, Biotechnol. Bioeng., 1976, 18, 1751-1760.

20 S. W. Kang, Y. S. Park, J. S. Lee, S. I. Hong and S. W. Kim, Bioresour. Technol., 2004, 91, 153-156.

21 M. J. Bailey, M. Siika-Aho, A. Valkeajarvi and M. E. Penttila, Biotechnol. Appl. Biochem., 1993, 17(Pt 1), 65-76.

22 C. Cummings and T. Fowler, Curr. Genet., 1996, 29, 227-233.
23 F. H. Arnold and G. Georgiou, Curr. Opin. Biotechnol., 2001, 12, 545-551.

$24 \mathrm{H}$. Zhao, K. Chockalingam and Z. Chen, Curr. Opin. Biotechnol., 2002, 13, 104-110.

25 J. F. Reidhaarolson and R. T. Sauer, Science, 1988, 241, 53-57. 26 W. P. Stemmer, Nature, 1994, 370, 389-391.

27 Y. An, L. Chen, S. Sun, A. Lv and W. Wu, New Biotechnol., 2011, 28, 320-325.

28 H. Nakazawa, K. Okada, T. Onodera, W. Ogasawara, H. Okada and Y. Morikawa, Appl. Microbiol. Biotechnol., 2009, 83, 649-657.

29 L. Lin, C. Fu and W. Huang, Enzyme Microb. Technol., 2016, 86, 52-58.

30 L. D. Plessis, S. H. Rose and W. H. van Zyl, Appl. Microbiol. Biotechnol., 2010, 86, 1503-1511.

31 J. Sambrook, E. F. Fritsch and T. Maniatis, Molecular Cloning: A Laboratory Manual, Cold Spring Harbor Laboratory, New York, 2012.

32 D. E. G. A. Adams, C. A. Kaiser and T. Stearns, Methods in Yeast Genetics, Cold Spring Harbor Laboratory Press, 1998.

33 J. J. Clare, M. A. Romanes, F. B. Rayment, J. E. Rowedder, M. A. Smith, M. M. Payne, K. Sreekrishna and C. A. Henwood, Gene, 1991, 105, 205-212.

34 W. P. C. Stemmer, Proc. Natl. Acad. Sci. U. S. A., 1994, 91, 10747-10751.

35 T. Zhan, K. Zhang, Y. Chen, Y. Lin, G. Wu, L. Zhang, P. Yao, Z. Shao and Z. Liu, PLoS One, 2013, 8, 724e-734e.

36 C. Kaiser, S. Michaelis and A. Mitchell, Methods In Yeast Genetics: A Cold Spring Harbor Laboratory Course Manual, Cold Spring Harbor Laboratory Press, 2000.

37 J. Hill, K. A. G. Donald and D. E. Griffiths, Nucleic Acids Res., 1991, 19, 5791.

38 IUPAC, Pure Appl. Chem., 1987, 59, 257-268.

39 X. H. Li, H. J. Yang, B. Roy, E. Y. Park, L. J. Jiang, W. Dan and Y. G. Miao, Microbiol. Res., 2010, 165, 190-198.

40 L. A. Kelley, S. Mezulis, C. M. Yates, M. N. Wass and M. J. Sternberg, Nat. Protoc., 2015, 10, 845-858.

41 J. D. Thompson, T. J. Gibson and D. G. Higgins, Current Protocols in Bioinformatics, Wiley, USA, 2002, ch. 2, pp. 2.3.1-2.3.22.

42 W. L. Delano, The PyMOL Molecular Graphics System (v. 1.5.0.1), Schrödinger LLC, New York, USA, 2013.

43 M. A. Larkin, G. Blackshields, N. P. Brown, R. Chenna, P. A. McGettigan, H. McWilliam, F. Valentin, I. M. Wallace, A. Wilm, R. Lopez, J. D. Thompson, T. J.Gibson and D. G. Higgins, Bioinformatics, 2007, 23, 2947-2948.

44 X. Wang, J. Fan, S. W. Zhu, B. J. Cheng and F. Tao, Acta Laser Biol. Sin., 2012, 21, 245-251.

45 G. Banerjee, S. Car, J. S. Scott-Craig, M. S. Borrusch, N. Aslam and J. D. Walton, Biotechnol. Bioeng., 2010, 106, 707-720.

46 C. Liang, M. Fioroni, F. Rodríguez-Ropero, Y. Xue, U. Schwaneberg and Y. Ma, J. Biotechnol., 2011, 154, 46-53.

47 M. H. Momeni, C. M. Payne, H. Hansson, N. E. Mikkelsen, J. Svedberg, Å. Engström, M. Sandgren, G. T. Beckham and J. Ståhlberg, J. Biol. Chem., 2013, 288, 5861-5872.

48 I. Kwon, K. Ekino, M. Goto and K. Furukawa, Biosci., Biotechnol., Biochem., 2014, 63, 1714-1720. 
49 B. Tang, H. Pan, Q. Zhang and L. Ding, Bioresour. Technol., 2009, 100, 6129-6132.

50 P. J. Kraulis, G. M. Clore, M. Nilges, T. A. Jones, G. Pettersson, J. Knowles and A. M. Gronenborn, Biochemistry, 1989, 28, 7241-7257.

51 C. Divne, I. Sinning, J. Ståhlberg, G. Pettersson, M. Bailey, M. Siika-Aho, E. Margolles-Clark, T. Teeri and T. A. Jones, J. Mol. Biol., 1993, 234, 905-907.

52 T. T. Teeri, T. Reinikainen, L. Ruohonen, T. A. Jones and J. K. C. Knowles, J. Biotechnol., 1992, 24, 169-176.

53 F. Tao, X. Wang, H. Y. Jiang, J. Fan, S. W. Zhu and B. J. Cheng, Acta Laser Biol. Sin., 2011, 20, 809-814.

54 W. Duntze, V. Mackay and T. R. Manney, Science, 1970, 168, 1472-1473.

55 G. J. Kleywegt, J. Y. Zou, C. Divne, G. J. Davies, I. Sinning, J. Ståhlberg, T. Reinikainen, M. Srisodsuk, T. T. Teeri and T. A. Jones, J. Mol. Biol., 1997, 272, 383-397.
56 H. A. Chokhawala, C. M. Roche, T. W. Kim, M. E. Atreya, N. Vegesna, C. M. Dana, H. W. Blanch and D. S. Clark, BMC Biotechnol., 2015, 15, 1-12.

57 B. X. Yan and Y. Q. Sun, J. Biol. Chem., 1997, 272, 3190-3194.

58 J. L. Rahikainen, J. D. Evans, S. Mikander, A. Kalliola, T. Puranen, T. Tamminen, K. Marjamaa and K. Kruus, Enzyme Microb. Technol., 2013, 53, 315-321.

59 A. Nakamura, F. Fukumori, S. Horinouchi, H. Masaki, T. Kudo, T. Uozumi, K. Horikoshi and T. Beppu, J. Biol. Chem., 1991, 266, 1579-1583.

60 B. W. Matthews, H. Nicholson and W. J. Becktel, Proc. Natl. Acad. Sci. U. S. A., 1987, 84, 6663-6667.

61 B. Imperiali and S. E. O'Connor, Curr. Opin. Chem. Biol., 1999, 3, 643.

62 G. T. Beckham, Z. Dai, J. F. Matthews, M. Momany, C. M. Payne, W. S. Adney, S. E. Baker and M. E. Himmle, Curr. Opin. Biotechnol., 2012, 23, 338-345. 